\title{
AN INVESTIGATION OF COMMUNITY RESPONSE TO URBAN TRAFFIC NOISE
}

\author{
Gh. Mohammadi \\ Department of Industrial Engineering, Shahid Bahonar University of Kerman, Kerman, Iran \\ Received 19 August 2008; revised 10 May 2009; accepted 30 May 2009
}

\begin{abstract}
Traffic noise is a major environmental source of pollution in the whole planet, both in developed and in developing nations. The study being reported here has been carried out on one of the most busy and crowded streets in the downtown area of Kerman, located in south east of Iran, which have heavy traffic during the day. Total of 20 measuring points were selected along the main road and its 6 connecting streets. In this study the A-weighted continuous equivalent sound level values and statistical levels were manually measured at each site separately. The noise equivalent level varied between 66 to $79.5 \mathrm{dBA}$. The results of the study established the fact that noise levels are more than the acceptable limit of $60 \mathrm{dBA}$, which is the daytime governmentally prescribed noise limit for residential-commercial areas. This paper also describes the reaction of the environmental noise of the city of Kerman. A total of 250 questionnaires were processed. The results of the interview questionnaire revealed the following items; (I) the main isolated noise source was traffic (50\%) and street noise (34\%); (II) $70 \%$ of the people classified the noise in his/her street as "very high"; (III) 52\% and 48\% of the respondents answered that noise bother them more in morning and evening, respectively; (IV) $86 \%$ and $86.8 \%$ of the subjects answered that traffic noise produce physicsl and psychological annoyance to them; (V) the main outcomes of exposure to noise were: irritability (40.8\%), insomnia (24\%), difficulty in concentrating (16\%) and conservation disruption (16\%).
\end{abstract}

Keywords: Noise pollution, Traffic noise, Noise measurements, Noise annoyance, Community response

\section{INTRODUCTION}

Noise in big cities is considered by the World Health Organization (WHO) to be the third most hazardous type of pollution, right after air and water pollution (WHO, 2005). This study presents the results obtained from a social survey and noise measurements carried out in the city of Kerman, Iran. Kerman is one of the 30 provinces of Iran. The city of Kerman had an estimated population of 533,799 in 2005. The city of Kerman (population: 400,000) embraces about $80 \%$ of the urban population, being the most developed and largest city of the province. In Kerman, increase in population and in the number of circulating vehicles have led to an increase in the urban noise levels. The need for studies regarding the

*Corresponding author: gmohammadi@mail.uk.ac.ir Tel/fax: +98-341-2112861 urban noise pollution and its consequences for the community has motivated various researches on the problem in several countries (Arana and Garcia 1998; Suksaard et al., 1999; Abdel-Raziq and Zeid, 2000; Zannin et al., 2001; Zannin et al., 2003; Khilman, 2004; Piccolo et al., 2005).

Noise effects have various impacts on mental and physical health and disturbance in daily activities. It may affect sleep, conversation, leading to perception of annoyance and causes hearing loss, cardiovascular problems as well as affecting task performance (Piccolo, 2005).

The objective of this survey was to investigate the noise pollution leveland its impact on the community. This research represents the first study of community noise levels in the city of Kerman, located in south eastern part of Iran. 


\section{MATERIALS AND METHODS}

Sound level measurements

This study was focused on one of the most busy and crowded streets in the downtown area along with its 6 connecting streets, which have heavy traffic during the day. Total of 20 measuring points were selected along the roads, pavements and in the shopping areas of the city center to adequately represent the different acoustically residential-commercial situations.

Eight points was selected along the main street (Shariati) and two points were selected along each connecting streets. Researchers have reported that it is possible to determine the equivalent level representative of the equivalent annual level by means of sampling. They showed that 6 to 9 days random days sampling may result in 96\% to $99 \%$ accuracy providing on the possibility to determine it within the $\pm 2 \mathrm{~dB}$ range (Gajaa et al., 2003). In this study the A-weighted continuous equivalent sound level values $\left(\mathrm{L}_{\text {Aeq }}\right)$, peak noise levels during the measurement period, $\left(\mathrm{L}_{\max }\right)$ and statistical levels of $\mathrm{L}_{10}, \mathrm{~L}_{50}, \mathrm{~L}_{90}$ and $\mathrm{L}_{99}$ were manually measured at each site separately. The traffic noise index, (TNI) was computed from the noise database. The traffic noise index is a method used to estimate annoyance responses due to traffic noise, which is computed using the following formula (Langdon and Scholes, 1968):

$$
\mathrm{TNI}=4\left(\mathrm{~L}_{10}-\mathrm{L}_{90}\right)+\mathrm{L}_{90}-30
$$

The measurements were taken on various days of the week, except for Friday, from 07:00 a.m. to 22:00 p.m. Noise levels were measured 1.5 $\mathrm{m}$ above ground using a Class I 2231 Bruel and Kjaer integrating sound level meter with a 4230 $\mathrm{B}$ and $\mathrm{K}$ calibrator. During the study there was no wind and no rain in the environmental.

\section{Questionnaire description}

In order to know the opinion of the citizens from the area about how the noise levels have affected their daily life, a questionnaire was developed. The survey questionnaire contained four different parts. The first part had three questions, where the interviewer was identified as to sex, age and educational level. The second part had three questions, where information about accommodation characteristics was obtained. The third part had fourteen questions, where information about noise levels and its effects on people's habit was obtained.

In the last part, with five questions, the main noise type and its variation with time were evaluated. A reliability analysis (Cronbachs alpha) was performed on all 25 parts for the 250 subjects that completed the questionnaire during the study. The alpha value was 0.76 , which is considered to be acceptable, as suggested in Greenspoon and Saklofske (1998).

The respondents participating to the survey, were randomly selected on a one-person per family basis at the residential areas of the main street and its 6 connecting streets. A total of 250 questionnaires were processed.

\section{Questionnaire results}

Among the participants in the survey, 40\% were male and $60 \%$ were female, and their age was between 18 and >50 years old, 32\% were in the age group 18-30 years old, 40\% between 30 and 50 and 28\% were over 50.

A new method of grouping the noise sources was adopted: (a) the traffic noise generated by the vehicle flow in the urban streets; (b) the neighborhood noise that surrounds the nearby residential areas surveyed (generated by neighbors, animals, civil constructions, fireworks, electrical appliances, toys and others); and other sources (noise generated by residential alarms, etc., inside the houses).

\section{RESULTS}

\section{Measurement results}

Table 1 displays the mean values for $\mathrm{L}_{\text {Aeq }}, \mathrm{L}_{\text {max }}$ and statistical values of $\mathrm{L}_{10}, \mathrm{~L}_{50}, \mathrm{~L}_{90}$ and $\mathrm{L}_{99}$ for Shariati and its 6 connecting streets at all measurement stations. The noise equivalent level $\mathrm{L}_{\text {Aeq }}$ varied between 66 to $79.5 \mathrm{dBA}$ at these locations. The maximum and minimum values were 79.5 and 66 dBA, respectively. An overview of the Table 1 reveals that $\mathrm{L}_{\text {Aeq }}$ have a maximum value of 79.5 $\mathrm{dBA}$, indicating that they exceed the governmental legislations for residential-commercial area (IDE, 1998).

The frequency distributions of the subjects concerning the noise types in their houses 
Iran. J. Environ. Health. Sci. Eng., 2009, Vol. 6, No. 2, pp. 137-142

Table 1: The means of noise levels in 20 stations in Kerman

\begin{tabular}{|c|c|c|c|c|c|c|c|}
\hline Stations & $\mathrm{L}_{\max }$ & $\mathrm{L}_{\text {Aeq }}$ & $\mathrm{L}_{99}$ & $\mathrm{~L}_{90}$ & $\mathrm{~L}_{50}$ & $\mathrm{~L}_{10}$ & TNI \\
\hline \multicolumn{8}{|c|}{$\begin{array}{c}\text { Main downtown street } \\
\text { Station No. }\end{array}$} \\
\hline 1 & 85.12 & 69.7 & 59.7 & 62.9 & 68.5 & 72.7 & 72.1 \\
\hline 2 & 80.1 & 68.4 & 58.1 & 62.7 & 64.2 & 71.4 & 67.5 \\
\hline 3 & 83.5 & 70.9 & 62.1 & 65.9 & 69.1 & 73.9 & 67.9 \\
\hline 4 & 79.7 & 66 & 57.8 & 59.9 & 59 & 69 & 66.3 \\
\hline 5 & 79.7 & 68.1 & 59 & 61.7 & 65.1 & 71.1 & 69.3 \\
\hline 6 & 87.3 & 77.4 & 68.8 & 72.3 & 75.7 & 80.4 & 74.7 \\
\hline 7 & 89.8 & 77.4 & 68.8 & 71.8 & 75.8 & 80.4 & 76.2 \\
\hline 8 & 86.5 & 77.9 & 68.3 & 70.7 & 73.6 & 80.9 & 81.5 \\
\hline \multicolumn{8}{|c|}{$\begin{array}{c}6 \text { connecting streets } \\
\text { Station No. }\end{array}$} \\
\hline 1 & 80.9 & 66.5 & 57.9 & 60 & 59.1 & 71.4 & 75.6 \\
\hline 2 & 80.9 & 68.7 & 59.2 & 61.9 & 65.5 & 71 & 68.3 \\
\hline 3 & 86.6 & 70.4 & 59.9 & 63.2 & 69.1 & 73.2 & 73.2 \\
\hline 4 & 81.3 & 69 & 58.2 & 63 & 64.6 & 70 & 61 \\
\hline 5 & 86.3 & 70.4 & 59.9 & 63.2 & 69.1 & 73.2 & 73.2 \\
\hline 6 & 88.9 & 78.5 & 69.4 & 73.1 & 76.7 & 80.7 & 73.5 \\
\hline 7 & 91.5 & 78.5 & 69.4 & 72.6 & 76.8 & 83.1 & 84.6 \\
\hline 8 & 93.5 & 79.5 & 69.4 & 72.6 & 76.8 & 83.1 & 84.6 \\
\hline 9 & 80.3 & 68 & 57.2 & 62 & 63.6 & 69 & 60 \\
\hline 10 & 83.9 & 70.6 & 61.4 & 65.4 & 68.7 & 73.5 & 67.8 \\
\hline 11 & 87.5 & 77.6 & 70 & 72.4 & 74.5 & 83.1 & 85.2 \\
\hline 12 & 91.3 & 77 & 62 & 64.4 & 70.1 & 81.1 & 101.2 \\
\hline
\end{tabular}

are presented in Fig. 1. The major parts of the respondents (50\%) have answered that traffic noise is the major noise source, $34 \%$ emphasized on the noises from the street, and $16 \%$ on construction noises. In another question, the subjects have classified the noise in their houses as "very high" (70\%), "high" (18\%), and "normal" (12\%). Fig. 2 displays frequency distributions of subjects concerning the noise levels. More than half of the respondents have affirmed that they had been living at the same home for more than 5 years, $40 \%$ had been living at the same home for 1 to 5 years and $10 \%$ had been living at the same location for less than one year.

The respondents have been asked "what time does noise bother them more". For this question,

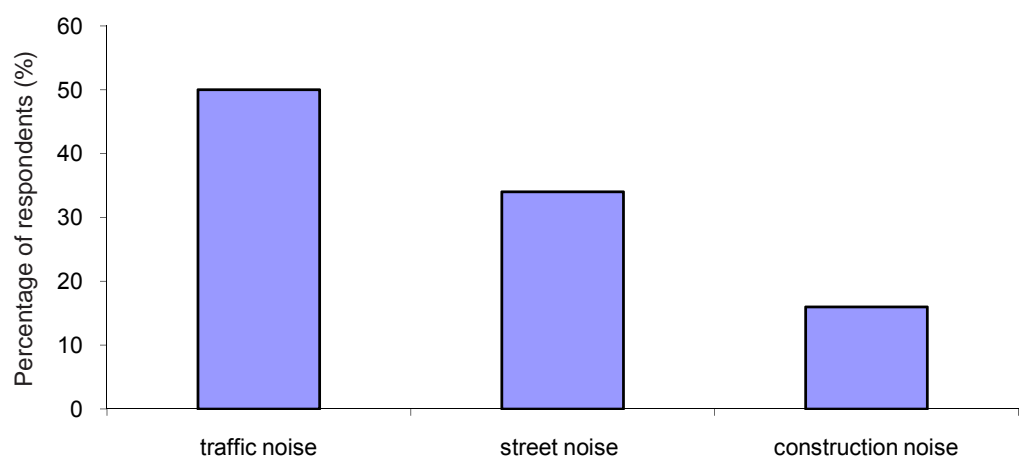

Fig. 1: Frequency distribution of answers concerning types of noises 


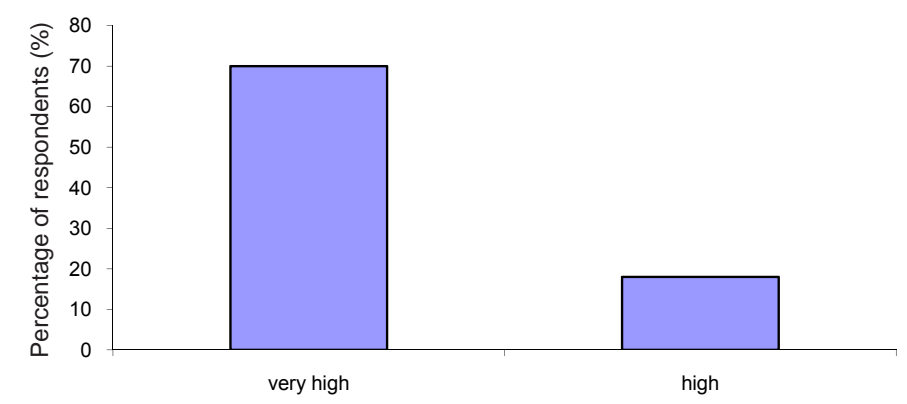

Fig. 2: Frequency distributions of answers concerning levels of street noises

$52 \%$ out of them answered that noise bother them in the morning (07:00-12:00) and 58\% answered that noise bother them more in the evening (13:00-22:00).

Asked about "what kind of noise you hear in your house/flat", the majority of the respondents (50\%) have pointed the traffic, followed by the street (34\%) and (16\%) construction noises. No doubt the traffic is a continuous noise source, as well as street and construction in many cases.

The majority of the respondents have answered that they sometimes felt annoyed by noise in his/her home and have pointed out that at least one of these noncontiguous sources were the cause of annoyance. The frequency distributions of the answers regarding physical and psychic annoyance of traffic noises are displayed in Fig. 3 . Nearly $86 \%$ of the respondents have answered that traffic noise produced physical annoyance $86.8 \%$ have answered that noise produced psychic to them.

Types of negative impacts on the health of residents are shown in Fig. 4.

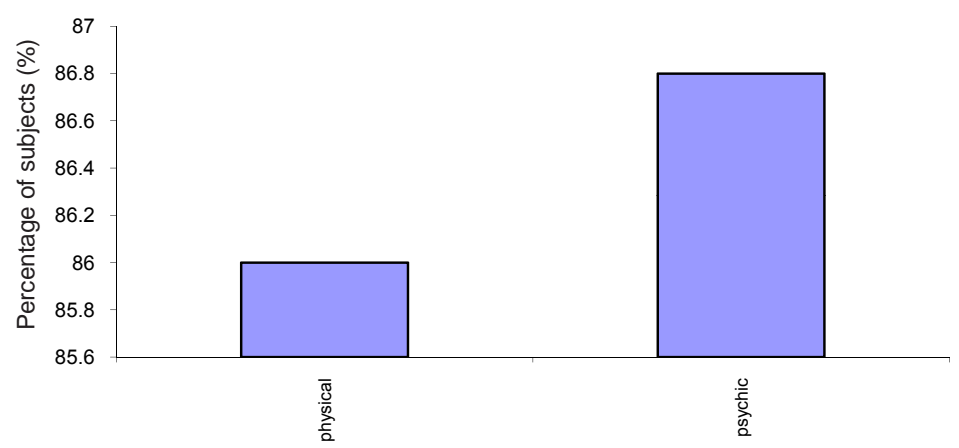

Fig. 3: Frequency distributions of answers regarding physical and psychic annoyance produced by high noise levels

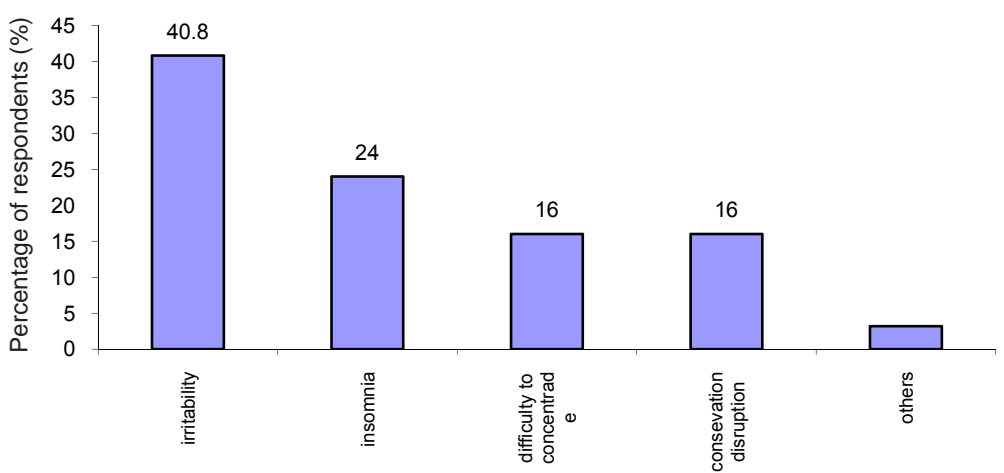

Fig. 4: Respondents answers to the question "what does the noise causes on you?” 


\section{DISCUSSION}

Pollution in big cities is a growing problem due to the fact that the urban environment is becoming increasingly crowded and busy.

In this research, noise levels were measured in the center of Kerman along with its 6 connecting streets. Simultaneously with measurements of noise, the opinion of 250 residents that lived in the area, concerning their level of annoyance, traffic noises, as well as the health impact of noise, was surveyed.

The measured noise levels and the traffic noise index indicted that the noise levels were generally high; $\mathrm{L}_{\text {Aeq }}$, ranged between a maximum of 79.5 (dBA) and a minimum of 66 (dBA).

Nearly $52 \%$ of subjects believed that noise bothered them more in the morning and $48 \%$ in the evening, as is also reported by other researches (Uris and Cervera, 2001).

The study has revealed that the more unpleasant noise was traffic noise followed by street and construction noises. This part of the study was in agreement with other studies (Saadu et al.1998; Ouis, 2001).

Interesting results have also been obtained regarding the annoyance levels (psychic and physical) and the nature of the noise source. If the sources are analyzed separately, it is noticeable that among the subjects who felt annoyed by the noise in his/her home, $50 \%$ pointed out the traffic noise was the main source of annoyance, $34 \%$ the street noise.

Findings of the study showed that traffic noise has negative impacts on human health, as is reported by others (Mato and Mufuruki, 1999; Georgiadou et al., 2004).

Maschke (2001) and Babisch et al. (1999) have pointed out some effects of the noise over urban inhabitants: irritability, insomnia, difficulty to concentrate and headaches. It has been observed that everybody within the group "Annoyed by Urban Noise" had declared that they felt at least one of the effects related above.

\section{ACKNOWLEDGEMENTS}

The author would like to thank the Editor-in-Chief IJEHSE for helpful comments and suggestions. The insightful comments of the reviewers are also greatly acknowledged.

\section{REFERENCES}

Abdel-Raziq, I R, Zeid, Q and Seh, M, (2000). Noise measurements in the community of Nablus in Palestine, Acoustical, 86: 578-580.

Arana, M and Garcia, A., (1998). A social survey on the effects on environmental noise on the residents of Pamplona, Spain, Applied Acoustics, 53: 245-253.

Babisch W., Ising H., Gallacher JEJ, Sweetnan PM, Elwood PC. (1999). Traffic noise and cardiovascular risk: the Caerphilly and Speedwell studies third phase-10-year to follow up, Arch Environ Health, 54(5): 210-216.

Georgiadou, E., kourtidis, K., ziomas, I., (2004). Exploratory traffic noise Measurements at five main streets of Thessaloniki, Greece, Global Nest I International Journal, 6(1):53-61.

Gajaa, E., Gimenezb, A., Sanchoa, A.S. Reiga, S.A. (2003). Sampling techniques for the estimation of the annual equivalent noise level under urban traffic conditions Applied Acoustics. 64: 43-53.

Greenspoon, P., Saklofske, E., (1998).Confirmatory factor analysis of the Multidimensional student's Life satisfaction scale. Personality an Individual Differences, 25,965-971.

Iran Department of Environment, (IDE), (1998). Environmental Standards and regulations, IDE. Press Tehran.

Khilman, T., (2004). Noise pollution in cities, Curtiba and Totenberg as examples In: proceedings of the seminarEnvironmental Aspects of Urbanization-Seminar in Honor of Dr. Motafa Kamal Tolba, Gothenburg, Sweden, in CD.

Langdon, F. J. and Scholes, W. E. (1968). 'The traffic noise index: A method of controlling noise nuisance', Building Research Current Papers 38168, 2-3.

Maschke C., (2001). Preventive medical limits for chronic traffic noise exposure, Acustica, 85(5):448.

Mato, R.R., Mufuruki, T.S., (1999).Noise pollution associated with the operation of the Dares Salaam International Airport, Transportation Research Part D, 81-89.

Ouis, D., (2001).Annoyance from road traffic noise; a review, journal Enviro psychol 21(5):101-20.

Piccolo, A. Plutino, D. Cannistraro, G., (2005). Evaluation and analysis of the environmental noise of Messin, Italy, Apl. Acoust, 66(40):447-465.

Suksaard, T, Sukasem, P, Tabucanon, S M, Aoi, I, Shirai, $\mathrm{K}$ and Tanaka, H., (1999). Road traffic noise prediction model in Thailand, Applied Acoustics, 58: 123-130.

Saadu, A.A., Onyeonwn, R.O., Ayorinde, E.O., Ogisi, F.O., (1998). Road traffic noise Survey and analysis of source major urban centers in Nigeria, Noise the controls Eng.J., 46(5):146-58.

Uris, A., Cervera, F., (2001).Community response to road traffic noise in the littoral Region near Valencia (Spain), International Jr. of Environmental Heath Research, 11:349-355.

Zannin, P H T, Diniz, F, Calixto, A and Barbosa, W., (2001). Environmental noise pollution in residential areas of the city of Curitiba, Acoustical, 87, 1-4.

Zannin, P H T, Calixto, A, Diniz and F, Ferreira, J A., 
(2003). A survey of urban noise annoyance in a large Brazilian city: the importance of a subjective analysis in conjunction with an objective analysis, Environmental Impact Assessment review, 23:245-255.

World Health Organization, (2005). United Nations Road Safety Collaboration: A Handbook of Partner Profiles (Geneva: World Health Organization). 